\title{
Associations between Drugs Administered during Pregnancy and Congenital Abnormalities of the Fetus
}

\author{
MATILDA M. NELSON, JOHN O. FORFAR
}

British Medical fournal, 1971, 1, 523-527

\section{Summary}

In a retrospective study to compare the drug consumption during pregnancy of mothers of infants with congenital abnormalities and of those without, over $97 \%$ of 1,369 mothers took prescribed drugs and $65 \%$ self-administered drugs. Significantly more mothers of infants with congenital abnormalities took aspirin, antacids, dextroamphetamine, phenobarbitone, sodium amytal, other barbiturates, cough medicines, iron, sulphonamides, and nicotinamide than mothers in the control group. However, most mothers taking analgesics, antacids, appetite suppressants, barbiturates, cough medicines, iron, sulphonamides, and vitamins produced normal infants. Any teratogenic effect of these drugs is therefore one of low potency. On the other hand, deficiencies such as those of ascorbic acid and folic acid may have a teratogenic effect. There is need for caution in presuming teratogenic effects on the basis of the associations shown here. During pregnancy, however, it would appear wise to avoid the administration of any drug which carries a suspicion of teratogenicity unless that drug is specifically indicated, and selfmedication with common household remedies such as aspirin and antacids should be avoided. These recommendations would also apply to any woman of childbearing age in whom conception is likely.

\section{Introduction}

As part of a survey into the aetiology of congenital malformations the drug consumption of pregnant mothers, both of prescribed and of self-administered drugs, was studied over a period of two years in three hospital maternity units.

\section{Patients}

During the study period 458 mothers gave birth to infants with congenital abnormalities (175 with major and 283 with minor abnormalities). The pattern of these has already been reported (Nelson and Forfar, 1969). A control group consisted of 500 mothers of the next normal babies born after the congenitally abnormal ones in the same maternity units and of a further 411 mothers of normal babies matched in respect of maternal age and parity and babies' sex with a similar number in the study group. The mean age and parity of the mothers in the study group were 26.8 years and 1.9, respectively, and in the control group 26.2 years and 1.5, respectively.

\section{University of Edinburgh}

MATILDA M. NELSON, M.R.C.P.ED., D.C.H., Formerly Research Fellow, Department of Child Life and Health (Present appointment: Lecturer, Department of Human Genetics)

JOHN O. FORFAR, M.D., F.R.C.P. (LOND., ED.), Professor of Child Life and Health

\section{Method of Inquiry}

All mothers were interviewed before discharge from the maternity units, and a questionnaire covering drugs consumed during pregnancy-including type, timing of consumption, and amount-was completed. Pregnancy calculated from the first day of the last menstrual period, was subdivided into $(a)$ the first 14 days, the prefertilization period; $(b)$ the first 56 days, the period of maximum organogenesis; and $(c)$ the first trimester, the period of total organogenesis.

Of the $\mathbf{2 6 8}$ general practitioners of mothers included in the survey $53 \%$ were seen personally, $37 \%$ provided information by telephone and/or questionnaire, and $10 \%$ ignored all approaches. In the hospitals the antenatal and other outpatient records and inpatient records were studied.

Finally, an attempt was made to recover the prescriptions issued to the mothers as proof that they had been taken for dispensing and as a record of the drugs supplied. In the case of prescriptions taken to private (non-hospital) pharmacists for dispensing, these are returned to the Scottish Home and Health Department pricing bureau and batched under the name of the dispensing pharmacy. All scripts (E.C. 10s) from the relevant pharmacies for the 12 months before the baby's date of birth were scanned and any relevant prescription forwarded to us for examination. Altogether about 20,000,000 scrutinies of prescriptions were made, taking 21 months. At least 60 prescriptions $(1.6 \%)$ were submitted by chemists which had not been mentioned by the patient.

In deciding whether a mother had consumed a drug her statement that she had taken it had to be corroborated (the "double check") from at least one other source-general practitioner, hospital records, or pricing bureau. Only where the mother was a hospital inpatient was the entry of a drug on her treatment chart taken as valid evidence of consumption without confirmation from her. If a drug was administered at any time throughout the whole period of pregnancy, including the first trimester, it was noted as being given during the "whole of pregnancy."

\section{Results}

\section{ANALYSIS OF PRESCRIPTIONS}

Of the 1,333 mothers to whom prescriptions were reported to have been issued 122 had forgotten the pharmacist to whom the prescription had been taken, had had the prescription dispensed in another region, or had no prescription available for technical reasons. Of the remaining 1,211 mothers $61 \%$ had some or all of their prescriptions traced through the pricing bureau. Possible reasons for non-recovery were that the mother had identified the pharmacy wrongly or had not taken the prescription to a pharmacy, or that the prescription had been overlooked in the pricing bureau search. The sources of the 4,929 prescriptions issued are shown in Table I. Of the total number 1,408 were dispensed by hospitals and were not therefore recoverable through the pricing bureau. Of the remainder $65 \%$ were recovered through the pricing bureau$68 \%$ of general-practitioner prescriptions and $50 \%$ of hospital prescriptions, which suggests that mothers are more likely to obtain medicines prescribed by their own doctor than by hospitals where the prescription has to be dispensed outside. 
TABLE I-Sources of Prescriptions to Pregnant Mothers (Information from Mothers, General Practitioners, Hospital Records, and Pricing Bureau)

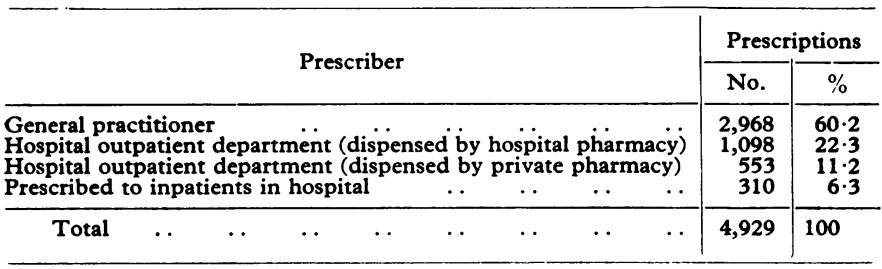

TABLE II-Prescribed Drugs

\begin{tabular}{|c|c|c|c|c|c|c|c|c|}
\hline \multirow{3}{*}{$\begin{array}{c}\text { No. of } \\
\text { Drugs Taken }\end{array}$} & \multicolumn{4}{|c|}{ Whole of Pregnancy } & \multicolumn{4}{|c|}{ First Trimester Only } \\
\hline & \multicolumn{2}{|c|}{$\begin{array}{c}\text { Abnormal } \\
\text { Group }\end{array}$} & \multicolumn{2}{|c|}{$\begin{array}{l}\text { Control } \\
\text { Group }\end{array}$} & \multicolumn{2}{|c|}{$\begin{array}{c}\text { Abnormal } \\
\text { Group }\end{array}$} & \multicolumn{2}{|c|}{$\begin{array}{l}\text { Control } \\
\text { Group }\end{array}$} \\
\hline & No. & $\%$ & No. & $\%$ & No. & $\%$ & No. & $\%$ \\
\hline $\begin{array}{l}\text { None } \\
\text { One (excluding }\end{array}$ & 10 & $2 \cdot 1$ & 27 & $2 \cdot 9$ & 205 & $44 \cdot 8$ & 401 & $44 \cdot 0$ \\
\hline 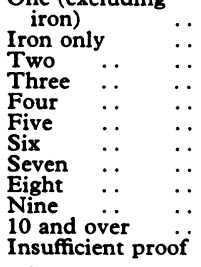 & $\begin{array}{r}21 \\
68 \\
87 \\
74 \\
65 \\
42 \\
32 \\
22 \\
9 \\
4 \\
11 \\
13\end{array}$ & $\begin{array}{r}4 \cdot 6 \\
14 \cdot 8 \\
19 \cdot 0 \\
16 \cdot 2 \\
14 \cdot 2 \\
9 \cdot 2 \\
7 \cdot 0 \\
4 \cdot 8 \\
1 \cdot 9 \\
0 \cdot 9 \\
2 \cdot 4 \\
2 \cdot 8\end{array}$ & $\begin{array}{r}32 \\
137 \\
152 \\
156 \\
143 \\
76 \\
56 \\
35 \\
17 \\
17 \\
14 \\
49\end{array}$ & $\begin{array}{r}3 \cdot 5 \\
15 \cdot 0 \\
16 \cdot 0 \\
17 \cdot 3 \\
15 \cdot 7 \\
8 \cdot 3 \\
6 \cdot 1 \\
3 \cdot 8 \\
1.8 \\
1.8 \\
1.5 \\
5 \cdot 4\end{array}$ & $\begin{array}{r}56 \\
65 \\
63 \\
29 \\
14 \\
8 \\
7 \\
1 \\
1 \\
1 \\
1 \\
7\end{array}$ & $\begin{array}{r}12 \cdot 2 \\
14 \cdot 2 \\
13 \cdot 8 \\
6 \cdot 4 \\
3 \cdot 1 \\
1.7 \\
1.5 \\
0 \cdot 2 \\
0 \cdot 2 \\
0.2 \\
0.2 \\
1.5\end{array}$ & $\begin{array}{r}126 \\
159 \\
115 \\
47 \\
29 \\
7 \\
9 \\
1 \\
2 \\
1 \\
-14\end{array}$ & $\begin{array}{r}13 \cdot 8 \\
17 \cdot 4 \\
12 \cdot 6 \\
5 \cdot 2 \\
3 \cdot 2 \\
0 \cdot 8 \\
1 \cdot 0 \\
0 \cdot 1 \\
0 \cdot 2 \\
0 \cdot 1 \\
1 \cdot 6\end{array}$ \\
\hline Total & 458 & $100 \cdot 0$ & 911 & $100 \cdot 0$ & 458 & $100 \cdot 0$ & 911 & $100 \cdot 0$ \\
\hline
\end{tabular}

Of the 4,731 prescriptions accepted as valid to this study $540(11.3 \%)$ had to be rejected because of absence of a double check. In 284 of these the mother's statement that she had taken the drug was not corroborated from any other source, and in 256 the mother did not confirm taking a drug of which there was evidence of prescription. Of the remaining 4,191 prescriptions the mother's statement was corroborated by the recovery of the prescription through the pricing bureau $(46.3 \%)$ or by evidence in general-practitioner $(11.1 \%)$, hospital inpatient $(7.1 \%)$, or hospital outpatient $(35.5 \%)$ records.

The numbers of prescribed drugs taken by mothers in the study group and in the control group during the whole of pregnancy and in the first trimester were similar at all stages of pregnancy (Table II); the average number taken during the whole of pregnancy was 3.5 for both study and control groups, and during the first trimester 2.1 and 1.8 respectively.

\section{EFFECT OF SPECIFIC DRUGS}

The main categories of drugs taken by mothers in both groups are shown in Table III. One entry was made for each mother taking a drug irrespective of the number of preparations containing that drug which she took. Many preparations contained several ingredients and each ingredient was entered specifically as consumed by the mother (Table IV). In only one or two situations (indicated below) did the dosage appear to have any critical effect.

Analgesics.-Analgesics were taken by a significantly higher proportion of mothers of infants with (a) "all" and "minor" abnormalities during the whole of pregnancy and $(b)$ all abnormalities during the first 56 days of pregnancy. Furthermore, aspirin was taken by a significantly higher proportion of mothers of all abnormal infants and of infants with major abnormalities in the whole of pregnancy and of infants with all abnormalities in the first trimester. Though there were no significant differences for aspirin for the first 56-day and 14day periods there was a significant difference for the first 28 day period, 8 out of 458 mothers in the all abnormalities group consuming aspirin at this time compared with 3 out of 911 in the control group $(P<0.05)$. The abnormalities in the eight babies of mothers taking aspirin during the first 28-day period were achondroplasia, hydrocephalus, congenital heart disease, mongolism, congenital dislocation of the hip, hydrocele, talipes, and papilloma of the forehead. The average dose of aspirin per mother in the study group was a little over half that in the control group.

Antacids.-The number of mothers taking antacids in the first trimester was significantly higher in the study group compared with the control group of mothers for all, major, and minor abnormalities. For major abnormalities this difference was also evident for the first 56-day period. In order of frequency the antacids consumed were magnesium carbonate, aluminium hydroxide, sodium bicarbonate, magnesium trisilicate, propantheline bromide, kaolin, belladonna, and calcium carbonate, but there were no significant differences with individual antacids.

Antiemetics.-Compared with controls significantly fewer mothers of infants with major abnormalities consumed antiemetics during the first trimester. Fewer mothers of infants with major abnormalities took promethazine theoclate during the first 56 days of pregnancy. Fewer mothers of infants with minor abnormalities took meclozine during the whole of pregnancy and the first trimester, and fewer mothers of infants with all abnormalities took buclizine during the first trimester. The most commonly consumed antiemetics in order of frequency were promethazine theoclate, prochlorperazine, meclozine, dicylomine, cvclizine, buclizine, trifluoperazine, chlorpromazine, and pipamazine.

Antihistamines.-In the first trimester significantly fewer mothers of infants with all and minor abnormalities took antibistamines compared with controls. No individual antihistamine was associated with a difference. In order of frequency the most commonly consumed antihistamines were promethazine hydrochloride, diphenhydramine, triprolidine hydrochloride, mepyramine maleate, diphenylpyraline, chlorpheniramine, chlorcyclizine, and trimeprazine.

Antibiotics.-No group or individual differences were evident for antibiotics (including cycloserine and nitrofurantoin). In order of frequency the main antibiotics taken were penicillin, tetracycline, streptomycin, nitrofurantoin, chloramphenicol, and cycloserine.

Appetite Suppressants.-These were taken by a higher

TABLE III-Types of Drugs Prescribed and Numbers and Proportions of Mothers Taking these Drugs in Abnormal and Control Groups

\begin{tabular}{|c|c|c|c|c|c|c|c|c|c|c|c|c|c|c|c|c|c|}
\hline \multirow{4}{*}{ Type of Drug } & \multirow{4}{*}{ 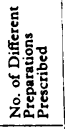 } & \multicolumn{4}{|c|}{ Whole of Pregnancy } & \multicolumn{4}{|c|}{ First Trimester } & \multicolumn{4}{|c|}{ First 56 Days of Pregnancy } & \multicolumn{4}{|c|}{ First 14 Days of Pregnancy } \\
\hline & & \multicolumn{3}{|c|}{ Abnormalities } & \multirow{2}{*}{$\begin{array}{c}\text { Controls } \\
(911)\end{array}$} & \multicolumn{3}{|c|}{ Abnormalities } & \multirow{2}{*}{$\begin{array}{c}\text { Controls } \\
(911)\end{array}$} & \multicolumn{3}{|c|}{ Abnormalities } & \multirow{2}{*}{$\begin{array}{c}\text { Controls } \\
(911)\end{array}$} & \multicolumn{3}{|c|}{ Abnormalities } & \multirow{2}{*}{$\begin{array}{c}\text { Controls } \\
(911)\end{array}$} \\
\hline & & All & $\begin{array}{c}\text { Major } \\
\text { (175) }\end{array}$ & $\begin{array}{c}\text { Minor } \\
(283) \\
\end{array}$ & & $\begin{array}{c}\text { All } \\
(458)\end{array}$ & $\begin{array}{c}\text { Major } \\
\text { (175) }\end{array}$ & $\begin{array}{c}\text { Minor } \\
(283)\end{array}$ & & $\begin{array}{c}\text { All } \\
\text { (458) } \\
\end{array}$ & $\begin{array}{c}\text { Major } \\
(175)\end{array}$ & 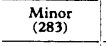 & & $\begin{array}{c}\text { All } \\
(458)\end{array}$ & $\begin{array}{c}\text { Major } \\
\text { (175) }\end{array}$ & $\begin{array}{l}\text { Minor } \\
(283)\end{array}$ & \\
\hline & & No. (\%) & No. $\left({ }^{\circ}, 0\right)$ & No. $(0)$ & No. (") & No. (") & No. $\left({ }^{\prime}(0)\right.$ & No. (") & No. (") & No. $\left({ }^{\circ}{ }_{0}\right)$ & No. ("..) & No. $(" a)$ & No. (".) & No. $\left({ }^{\circ},.\right)$ & No. (".,) & No. $\left({ }^{\prime \prime}, 0\right)$ & No. $(", .)$, \\
\hline 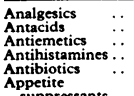 & $\begin{array}{l}23 \\
36 \\
15 \\
21 \\
34\end{array}$ & $\begin{array}{l}97(21.2 \dagger) \\
57(12.4) \\
65(14.2) \\
34(7.4) \\
77(16.8)\end{array}$ & $\begin{array}{l}34(19 \cdot 4) \\
20 \\
20(11.4) \\
12(11.4) \\
12(6.8) \\
33(18.3)\end{array}$ & $\begin{array}{l}63(22 \cdot 2+) \\
37(13.0) \\
45(15) .9) \\
22(77.8) \\
44(15.5)\end{array}$ & $\begin{array}{l}135(14.8) \\
100(11.0) \\
148(16.3) \\
62(6.8) \\
142(15.6)\end{array}$ & $\begin{array}{|cc|}32 & (7.0) \\
27 & (5.9+9) \\
48 & (10.5) \\
4 & (0.90 .) \\
19 & (4.5)\end{array}$ & $\begin{array}{|rl|}11 & (6 \cdot 3) \\
12 & \left(6.9^{*}\right) \\
13 & \left(7 \cdot 4^{*}\right) \\
2 & (1 \cdot 1) \\
10 & (5.7) \\
\end{array}$ & $\begin{array}{cc}21 & (7.4) \\
15 & (5.3 .) \\
35 & (12.4) \\
2 & (0.7 .) \\
9 & (3.2) \\
& \end{array}$ & \begin{tabular}{|cc}
45 & $(4.9)$ \\
24 & $(2.6)$ \\
$119(13.1)$ \\
26 & $(2.9)$ \\
51 & $(5.6)$ \\
&
\end{tabular} & $\begin{aligned} 19 & (4 \cdot 2 *) \\
12 & (2.6) \\
20 & (4 \cdot 4) \\
3 & (0.6) \\
11 & (2.4) \\
& \end{aligned}$ & $\begin{array}{ll}8 & (4 \cdot 6) \\
5 & (2.9 *) \\
5 & (2 \cdot 9) \\
1 & (0.5) \\
4 & (2 \cdot 3) \\
& \end{array}$ & $\begin{aligned} 11 & (4.2) \\
7 & (2.5) \\
15 & (5.3) \\
2 & (0.7) \\
7 & (2.5) \\
& \end{aligned}$ & $\begin{array}{ll}18 & (2.0) \\
6 & (0.6) \\
47 & (5.2) \\
4 & (0.4) \\
25 & (2.7) \\
& \end{array}$ & $\begin{array}{cc}5 & (1 \cdot 1) \\
3 & (0.6) \\
1 & (0 \cdot 2) \\
3 & (0.6)\end{array}$ & $\begin{array}{cc}2 & (1 \cdot 1) \\
3 & (1 \cdot 7) \\
1 & (0.5) \\
2 & (1 \cdot 1)\end{array}$ & $\begin{array}{l}\overline{3} \\
\overline{1} \\
\overline{(0.3)}\end{array}$ & $\begin{array}{ll}5 & (0.5) \\
1 & (0.1) \\
2 & (0.2) \\
2 & (0.2) \\
6 & (0.6) \\
& (0.6)\end{array}$ \\
\hline 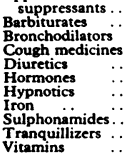 & $\begin{array}{l}26 \\
24 \\
11 \\
20 \\
10 \\
14 \\
28 \\
28 \\
15 \\
10 \\
41\end{array}$ & 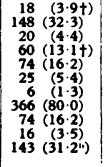 & 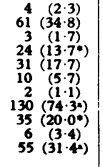 & $\begin{array}{c}77(2.5) \\
87(30.7) \\
177(6.0) \\
\left.360(12.7)^{*}\right) \\
43(15.2) \\
15(5.3) \\
44(1.4) \\
236(83.5) \\
39(13.8) \\
10((3.5) \\
88(31.04)\end{array}$ & $\begin{array}{r}10(1 \cdot 1) \\
255(28.0) \\
28(3.1) \\
76(8.3) \\
164(18.0) \\
37(4.1) \\
13(1.4) \\
746(82.0) \\
114(12.5) \\
33(3.6) \\
362(39.8)\end{array}$ & $\begin{aligned} 15 & \left(3.33^{*}\right) \\
43 & (9.4+) \\
5 & (1.1) \\
15 & (3.3) \\
2 & (0.4) \\
19 & (4.1) \\
3 & (0.6) \\
124 & (27.1) \\
17 & (3.7) \\
17 & (2.0) \\
40 & (8.7) \\
40 & (8.7)\end{aligned}$ & 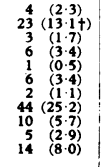 & $\begin{array}{rr}11 & (3 \cdot 9 *) \\
20 & (7.1) \\
2 & (0.7) \\
9 & (3.2) \\
1 & (0.3) \\
13 & (4.6) \\
1 & (0.3) \\
10 & (0.3) \\
80 & (28.2) \\
7 & (2.5) \\
4 & (1.4) \\
26 & (9 \cdot 2)\end{array}$ & $\begin{array}{rr}11 & (1 \cdot 2) \\
45 & (4.9) \\
12 & (1.3) \\
29 & (3.2) \\
29 & (0.2) \\
26 & (2.9) \\
1 & (0.1) \\
240 & (2 \cdot 4) \\
27 & (3.0) \\
13 & (1.4) \\
61 & (6.7) \\
61 & (6.7)\end{array}$ & $\begin{aligned} 13 & (2.8 .) \\
22 & (4.86) \\
1 & (0.2) \\
7 & (1.5) \\
1 & (0.2) \\
9 & (2.0) \\
1 & (0.2) \\
16 & (3.5) \\
16 & (3.5) \\
5 & (1.1) \\
7 & (1.5) \\
20 & (4.4+) \\
20 & (4.4)\end{aligned}$ & $\begin{aligned} 3 & (1.7) \\
11 & (6.3 \ddagger) \\
2 & (1.1) \\
1 & (0.5) \\
4 & (2.3) \\
1 & (0.5) \\
9 & (5.10) \\
2 & (1.1) \\
3 & (1.7) \\
10 & (5.7 .)\end{aligned}$ & \begin{tabular}{|cc|}
10 & $(3.5 \cdot)$ \\
11 & $(4.24)$ \\
1 & $(0.3)$ \\
5 & $(1.8)$ \\
\hdashline & -8 \\
5 & $(1 \cdot 8)$ \\
77 & $(2.5)$ \\
3 & $(0.7)$ \\
4 & $(1.4)$ \\
10 & $(3.5)$
\end{tabular} & $\begin{array}{rr}7 & (0.8) \\
18 & (2.0) \\
2 & (0.2) \\
12 & (1.3) \\
1 & (0.1) \\
9 & (1.0) \\
15 & (1.6) \\
14 & (1.5) \\
8 & (0.9) \\
15 & (1.6)\end{array}$ & $\begin{array}{cc}10 & (2 \cdot 2 *) \\
10 & \left(2 \cdot 2^{*}\right) \\
1 & (0.2) \\
1 & (0.2) \\
1 & (0 \cdot 2) \\
13 & (0.6) \\
1 & (0.6) \\
2 & (0.2) \\
4 & (0.4) \\
4 & (0 \cdot 9)\end{array}$ & 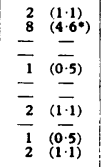 & $\begin{array}{cc}8 & \left(2.8^{*}\right) \\
2 & (0.7) \\
1 & (0.3) \\
\overline{1} & - \\
1 & (0.3) \\
1 & (0.3) \\
1 & (0.3) \\
1 & (0.3) \\
2 & (0.7)\end{array}$ & $\begin{array}{ll}4 & (0.4) \\
6 & (0.6) \\
1 & (0.1) \\
2 & (0.2) \\
1 & (0.1) \\
3 & (0.3) \\
3 & (0.4) \\
4 & (0.4) \\
4 & (0.4) \\
4 & (0.4) \\
4 & (0.4)\end{array}$ \\
\hline
\end{tabular}


TABle IV-Individual Drugs Prescribed and Numbers and Proportions of Mothers Taking these Drugs in Abnormal and Control Groups

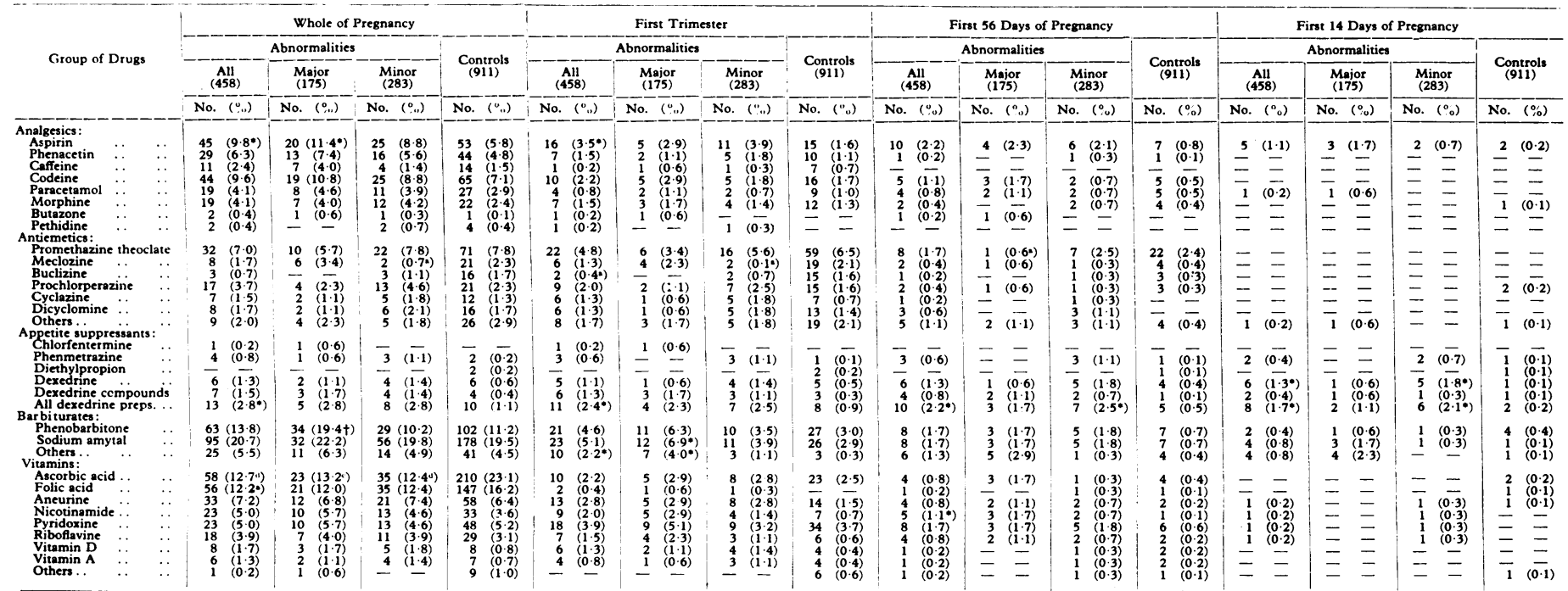

proportion of mothers of infants with $(a)$ all abnormalities during the whole of pregnancy and $(b)$ all and minor abnormalities during the first trimester, the first 56 days, and the first 14 days. Dextroamphetamine in particular was taken by a higher proportion of mothers of infants with (a) all abnormalities during the whole of pregnancy, the first trimester, the first 56 days, and the first 14 days, and (b) minor abnormalities during the latter two periods. The dosage taken of dextroamphetamine was significantly greater in the study group than in the control group. Four of the abnormal infants born to mothers taking dextroamphetamine during the first 56 days suffered from abnormalities of the urogenital system; other abnormalities were congenital heart disease, cleft lip, severe limb deformity, accessory auricles, congenital dislocation of the hip, and pilonidal sinus.

Barbiturates.-The proportion of mothers of infants with all and major abnormalities taking barbiturates in the first trimester, the first 56 days, and the first 14 days was very significantly higher than in the control group. A similar difference was seen for mothers of infants with minor abnormalities in the first 56 days. A higher proportion of mothers of infants with major abnormalities took phenobarbitone during the whole of pregnancy and sodium amytal during the first trimester. Other barbiturates (quinalbarbitone, pentobarbitone, and butobarbitone, etc.) were consumed by a higher proportion of mothers of infants with all and major abnormalities during the first trimester. For mothers of infants with all and major abnormalities the figures for sodium amytal and other barbiturates are just short of significance at the $5 \%$ level during the first 14 days. Sodium amytal then phenobarbitone were the most frequently prescribed barbiturates. Dosage tended to be higher in mothers giving birth to abnormal infants. Abnormalities associated with barbiturates were anencephaly (6), congenital heart disease (2), severe limb deformities, cleft lip and palate, intersex, congenital dislocation of the hip (4), soft-tissue deformity of the neck, hypospadias, accessory auricle, polydactyly, papilloma of the forehead, hydrocele, and naevus.

Bronchodilators.- No differences were evident between the two groups. Ephedrine, theophylline, and isoprenaline were the commonest drugs taken.

Cough Medicines.-A higher proportion of mothers of infants with all, major, and minor abnormalities than of control mothers took cough medicines during the whole of pregnancy. The most usual ingredients of cough mixtures were codeine phosphate, ammonium chloride, ammonium bicarbonate, and pholcodine.
Diuretics.- These were nearly all taken in late pregnancy. There were no significant differences between the groups.

Hormones.-Female hormones were usually given in early pregnancy as a diagnostic test for pregnancy and also for threatened premature labour or bleeding. Three mothers received corticosteroids and five thyroid. There were no group differences.

Hypnotics and Tranquillizers.-The number of mothers taking hypnotics and tranquillizers other than barbiturates was small and no differences were evident. The drugs consumed included dichloralphenazone, chloral hydrate, triclofos sodium, glutethimide, chlordiazepoxide, meprobamate, promazine, thioridazine, amitriptyline, and fluphenazine.

Iron.-During the first 56 days a significantly higher proportion of mothers of infants with major abnormalities took iron-containing preparations compared with the controls, whereas over the whole of pregnancy significantly fewer such mothers took iron. Ferrous sulphate was the most commonly prescribed preparation, followed by ferrous succinate, ferrous carbonate, ferrous fumarate, and ferrous gluconate. Nearly a third of mothers received iron in the first trimester.

Sulphonamides.-A higher proportion of mothers of infants with major abnormalities than of mothers in the control group took sulphonamides over the whole of pregnancy. The most commonly prescribed drugs were sulphadimidine, sulphamethizole, sulphadiazine, sulphamerazine, sulphathiazole, sulphaguanidine, and sulphamethoxypyridazine.

Vitamins.-During the first 56 days of pregnancy a higher proportion of mothers of infants with all and major abnormalities took vitamins and a higher proportion of mothers of infants with all abnormalities took nicotinamide. In contrast, throughout the whole of pregnancy significantly fewer mothers of infants with all, major, and minor abnormalities took vitamins in general and ascorbic acid in particular; significantly fewer mothers of infants with all abnormalities took folic acid. In order of frequency the most commonly prescribed vitamins were ascorbic acid, folic acid, aneurine, pyridoxine, nicotinamide, riboflavine, vitamin $D$, and vitamin $A$. The latter were often given in multiple vitamin preparations.

\section{SELF-ADMINISTERED DRUGS}

Consumption of self-administered drugs could be ascertained only by direct questioning of the mother. The number of mothers in the study and control groups taking self-medicated drugs were similar: two-thirds took them during the whole of 
TABI.E v-Proportions of Mothers Taking Self-medicated and Prescribed Aspirin and Antacids in Abnormal and Control Groups

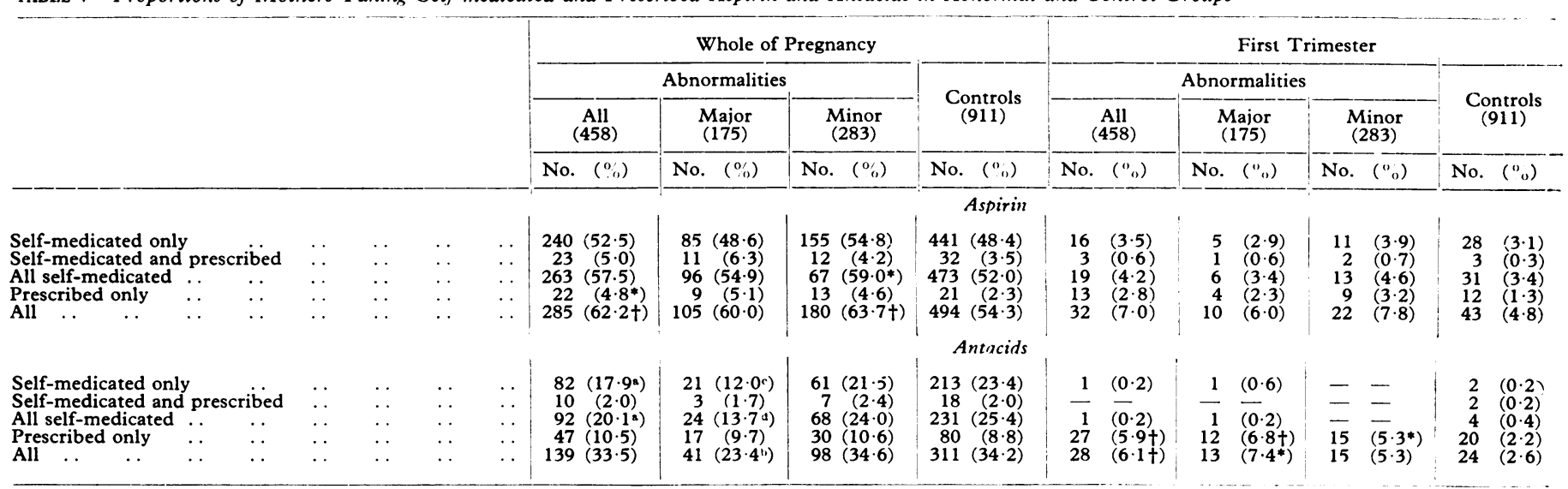

Percentages significantly higher than those in corresponding control group: ${ }^{*} \mathrm{P}<0.05 ;+\mathrm{P}<0.01$

Percentages significantly higher than those in corresponding control group: ${ }^{*} \mathrm{P}<0.05 ;+\mathrm{P}<0.01$.
Percentages significantly lower than those in corresponding control group: $\mathrm{P}<0.05 ;$ " $\mathrm{P}<0.01 ; \mathrm{P}<0.001 ;$ "P $<0.0001$

pregnancy, but only 1 in 20 during the first trimester. The number of self-medicated drugs taken is probably underestimated. These drugs were largely confined to analgesics and antacids (Table V).

Analgesics.-In the first trimester the number of mothers taking self-medicated and prescribed aspirin were similar, but throughout pregnancy the number taking self-medicated aspirin was five to six times that taking prescribed aspirin. The association of aspirin with congenital abnormalities, when both self-medicated and prescribed is considered, is shown in Table $\mathrm{V}$.

Antacids.-Antacids taken in the first trimester were nearly all prescribed. In later pregnancy more self-medicated than prescribed antacids were consumed. The association of antacids with congenital abnormalities, when both self-medicated and prescribed are considered, is shown in Table V.

\section{Discussion}

If the double-check method is a valid basis for estimating drug consumption by mothers the amount of drugs consumed could have been underestimated because either the mothers failed to remember that they had taken a prescribed drug or the records of the general practitioner or hospital did not show that the drug which the mother claimed she had taken had been prescribed. If we assume that both these groups of drugs had in fact been taken by the mothers the consumption of prescribed drugs would have been underestimated by $11 \%$. It is very unlikely, however, that all of the uncorroborated drugs were taken. Furthermore, the mothers may have consumed drugs prescribed for them or handed to them which they did not recollect and for which no record could be found. It seems unlikely that any large amount of drugs would have been consumed in this way. On the other hand, if a mother failed to admit to not taking a drug prescribed for her or if she took less than the amount prescribed, the amount of drugs taken would be overestimated.

In this study the possible effect of a drug is judged on statistical comparisons. In the case of many of the drugs the numbers were too small to show significant differences, and the fact that there was no evidence against a drug could not exonerate it from possible teratogenic effects. On the other hand, the consumption of a drug by a higher proportion of mothers giving birth to malformed infants as compared with the mothers of normal infants does not necessarily mean that that drug has a teratogenic effect. There could be at least four other explanations. Firstly, if a disease were responsible for the development of congenital abnormalities a drug taken to alleviate the symptoms of that disease might appear to be teratogenic. Secondly, symptoms produced in the mother by a conzenitally abnormal fetus might result in a significant association between any drug used for the treatment of these symptoms and the congenital abnormality. Thirdly, in the early weeks of pregnancy the incidence of certain severe malformations in the embryo may be 10 or more times that seen in stillborn and liveborn infants (Nishimura et al., 1966). Most of these abnormal embryos must be aborted. A drug inhibiting the spontaneous abortion of already malformed embryos might wrongly appear to be responsible for disturbing organogenesis, but the net effect would be similar. Finally, where a drug is given in combination with another a teratogenic effect of one might appear also to be present in the other.

Where a drug is consumed by fewer mothers of abnormal infants compared with those of normal infants there could be three possible explanations. A deficiency-for example, of a vitamin-might have a teratogenic effect; a drug might exert its effect by encouraging the abortion of abnormal fetuses; or abnormalities in the fetus associated with fewer of the usual symptoms of pregnancy could mean that mothers of abnormal infants took fewer drugs to alleviate these symptoms.

The increased occurrence of congenital abnormalities associated with analgesics appeared to be related to the aspirin content. The injection of salicylate into pregnant rats or oral consumption of salicylate by pregnant mice, in both instances in a dosage relatively many times that used in humans, can result in fetal malformations (Trasler, 1965; Warkany and Takacs, 1965). In a retrospective study Richards (1969) found that a significantly higher proportion of mothers of abnormal infants had taken salicylate during the first trimester as compared with a control group of mothers of normal infants.

The association between the administration of antacids during the first trimester of pregnancy and the first 56 days and the occurrence of congenital abnormalities, both major and minor, does not appear to have been recorded before.

Of the appetite suppressants dextroamphetamine appeared to be the agent associated with the occurrence of congenital abnormalities. Nora et al. (1967), in a prospective follow-up of 140 mothers, noted a similar relationship.

The most significant association between any drug or group of drugs and the occurrence of congenital abnormalities was seen with barbiturates. Richards (1969) found that sedatives had been consumed by a higher proportion of mothers of malformed infants than of normal controls. Crombie et al. (1970) found that a greater than expected number of prescriptions for barbiturates had been issued to mothers of congenitally abnormal infants. Similarly, a higher than expected incidence of congenital abnormalities was found in infants delivered of epileptic mothers taking anticonvulsive drugs, including barbiturates (Meadows, 1970). Gleiss (1968) 
reported cases of congenital clouding of the ocular lens attributed to maternal ingestion of barbiturates. Winberg (1963) considered that phenobarbitone played no part in the production of congenital abnormalities, but in Sweden the incidence of certain abnormalities, including those of the central nervous system, is very much lower than it is in Scotland. Nearly $9 \%$ of all National Health Service prescriptions are for barbiturates or barbiturate-containing drugs (Tattersall, 1965).

The greater consumption of cough medicines by mothers of abnormal infants might possibly be related to the retention of abnormal embryos which might otherwise have been aborted. Drugs such as codeine and pholcodine might act in this way.

So far there has been little evidence to suggest that sulphonamides are teratogenic in man, but they can produce malformations in animals (Smithells, 1966), and their association with major malformations in this survey raises the possibility of a similar effect on humans.

As regards the possible teratogenic effect of vitamins, particularly nicotinamide, Nogami and Ingalls (1967) produced spinal malformations in mice by the intraperitoneal injection of nicotinamide into the mother during the tenth day of pregnancy.

In the present study five categories of drugs and five individual drugs were consumed by significantly fewer mothers of abnormal infants than mothers of normal infants (Tables III and IV). Antacids, which in the first trimester or earlier were consumed by a higher proportion of mothers of abnormal infants, were taken by fewer mothers in this group when the whole of pregnancy was considered. Antiemetics, which also appeared to act beneficially, were consumed mostly during the first trimester of pregnancy. A possible explanation of the significantly lower consumption of antacids and antiemetics by mothers of abnormal infants is that these mothers may be less likely to suffer from dyspepsia later in pregnancy, or morning sickness than mothers of normal infants. Of the individual antiemetic drugs showing a seemingly beneficial effect meclozine is of particular interest in view of the fact that it has been suggested as a possible teratogenic agent (Lenz, 1966). Like ourselves, Mellin (1964) found that a higher proportion of mothers of normal infants than of abnormal infants had consumed meclozine during the first trimester. There is also no support in our findings for the suggestion that cyclizine might have a teratogenic effect (British Medical Fournal, 1963).

Whereas in the first 56 days of pregnancy vitamins and iron were consumed by a significantly higher proportion of mothers of abnormal infants the reverse was the case when the whole of pregnancy was considered. The apparently protective effect of vitamins was related specifically to ascorbic acid and folic acid. Folic acid deficiency has been shown to have a teratogenic effect in rats, maximal between the eighth and tenth days of pregnancy (Nelson, 1960), and a similar effect may be evident in humans (Hibbard and Smithells, 1955). Folic acid antagonists may also induce human congenital malformations (Thiersch, 1960; Milunsky et al., 1968). Other vitamin deficiencies such as riboflavine deficiency in the rat can be associated with congenital malformations (Mackler, 1969).

Dosage did not appear to play an important part in the associations between maternal consumption of drugs and congenital abnormalities in our series.

We wish to thank Dr. A. J. Keay, Dr. T. N. MacGregor, Dr. A. F. Anderson, Dr. G. D. Matthew, Dr. J. D. O. Loudon, and Dr. R. Whitelaw for access to patients under their care; the many general practitioners who so kindly provided information; Miss Eva Cruickshank and Miss Eileen Miller for secretarial help; and Messrs. Ciba Ltd. and the Distillers Company Ltd. for generous grants.

We are particularly grateful to Dr. J. H. F. Brotherston, Chief Medical Officer, Scottish Home and Health Department, for facilitating and supporting the prescription search carried out by the pricing bureau; to Mr. R. Dickson and Mr. A. E. D. Bell for organizing the search; and to the 12 searchers who carried it out.

\section{References}

British Medical fournal, 1963, 1, 828

Crombie, D. L., Pinsent, R. J. F. H., Slater, B. C., Fleming, D., and Cross, K. W. (1970). British Medical Fournal, 4, 178.

Gleiss, J. (1968). Quoted in Birth Defects, 1969, 6, 195.

Hibbard, E. D., and Smithells, R. W. (1965). Lancet, 1, 1254.

Lenz, W. (1966). American fournal of Diseases of Children, 112, 99.

Mackler, B. (1969). Pediatrics, 43, 915. Meadows, R. (1970). Proceedings of the Royal Society of Medicine, 63, 48. 1169.

Milunsky, A., Graef, J. W., and Gaylor, M. F. (1968). Fournal of Pediatrics, 72,790 .

Nelson, M. M. (1960). In Ciba Foundation Symposium on Congenital Malformations, p. 151. London, Churchill.

Nelson, M. M., and Forfar, J. O. (1969). Developmental Medicine and Child Neurology, 11, 3.

Nishimura, H., Takano, K., Tanimura, T., Yasuda, M., and Uchida, T. (1966). Biology of the Neonate, 10,93.

Nogami, H., and Ingalls, T. H. (1967). Quoted in Birth Defects, 1968, 5, 258.

Nora, J. J., Nora, A. H., Sommerville, R. J., Hill, R. M., and McNamara, D. G., (1967). Fournal of the American Medical Association, 202, 1065. Richards, I. D. G. (1969). British fournal of Preventive and Social Medicine, 23,218 .

Smithells, R. W. (1966). Advances in Teratology, 1, 251.

Tattersall, R. (1965). Practitioner, 194, 68.

Thiersch, J. B. (1960). In Ciba Foundation Symposium on Congenital Malformations, p. 152. London, Churchill.

Trasler, D. G. (1965). Lancet, 1, 606.

Warkany, J., and Takacs, E. (1959). American fournal of Pathology, 35, 315.

Winberg, J. (1963). Bulletin de la Société Royale Belge de Gynécologie et d'Obstétrique, T33, 63. 